\title{
Bone mineral density change during adjuvant chemotherapy in pediatric osteosarcoma
}

\author{
Ju Hyun Ahn, MD', \\ Wan Hyeong Cho, MD², \\ Jun Ah Lee, MD', \\ Dong Ho Kim, MD', \\ Ju-Hee Seo, MD', \\ Jung Sub Lim, MD ${ }^{1}$
}

Departments of ${ }^{1}$ Pediatrics and ${ }^{2}$ Orthopedic Surgery, Korea Cancer Center Hospital, Seoul, Korea
Received: 22 July, 2015

Revised: 17 August, 2015

Accepted: 16 September, 2015

Address for correspondence: Jung Sub Lim, PhD, MD

Department of Pediatrics,

Korea Cancer Center Hospital, 75

Nowon-ro, Nowon-gu, Seoul 01812, Korea

Tel: +82-2-970-1224

Fax: +82-2-970-2427

E-mail: limjs@kcch.re.kr
Purpose: Osteoporosis is currently receiving particular attention as a sequela in survivors of childhood osteosarcoma. The aim of this study was to evaluate bone mineral density (BMD) changes during methotrexate-based chemotherapy in children and adolescents with osteosarcoma.

Methods: Nine patients with osteosarcoma were included in this retrospective study and compared with eight healthy controls. BMD of the lumbar spine and unaffected femur neck of patients was serially measured by dual-energy $x$-ray absorptiometry (DXA) before and just after chemotherapy and compared with controls.

Results: Four patients (44\%) showed decreased lumbar spine BMD and seven patients $(78 \%)$ showed decreased femur neck BMD, while all controls showed increased lumbar and femur BMD ( $P=0.024$ and $P=0.023)$. The femur neck BMD $z$-scores decreased from $-0.49 \pm 1.14$ to $-1.63 \pm 1.50(P=0.032)$. At the end of therapy, five patients (56\%) showed femur neck BMD $z$-scores below -2.0 .

Conclusion: The bone metabolism is disturbed during therapy in children with osteosarcoma, resulting in a reduced BMD with respect to healthy controls. Since a reduced BMD predisposes to osteoporosis, specific attention and therapeutic interventions should be considered.

Keywords: Osteosarcoma, Osteoporosis, Bone density, Korea

\section{Introduction}

Osteoporosis, a disease of decreased bone mass and strength and increased risk of fracture, is now considered to have a pediatric origin ${ }^{1)}$. Individuals who fail to achieve optimal peak bone mass (PBM) and strength during childhood and adolescence are more likely to develop osteoporosis later in life ${ }^{2)}$. Long-term survivors of childhood cancer (LTSCC) fail to achieve PBM and have a high prevalence of osteoporosis or low bone mineral density (BMD), even in early adulthood ${ }^{3,4}$. Thus, the Children's Oncology Group recommended a baseline evaluation of BMD at entry into long-term follow-up for LTSCC patients s. $^{5}$. Chemotherapy, radiotherapy, and hormone deficiencies are frequently cited as risk factors for osteoporosis in cancer patients ${ }^{3,4)}$. Children with acute lymphoblastic leukemia (ALL) were found to exhibit reduced lumbar spine BMD at diagnosis, and additional BMD loss was observed in approximately 50\% during treatment ${ }^{6,7)}$

Osteosarcoma is the most common primary malignant bone tumor in children and adolescents. The introduction of preoperative neoadjuvant chemotherapy has improved the survival and limb-salvage rate in osteosarcoma patients by decreasing the tumor burden before surgery ${ }^{8)}$. However, a high prevalence of osteoporosis and fracture was reported in longterm survivors of osteosarcoma even in unaffected limbs ${ }^{9,10}$. On the other hand, the study of changes in BMD during treatment for childhood osteosarcoma was not reported.

Thus, the aim of this study was to evaluate the changes in BMD during treatment for childhood osteosarcoma. To this end, we analyzed the BMD changes of osteosarcoma patients treated at Korea Cancer Center Hospital. 


\section{Materials and methods}

This study was a retrospective chart review of nine osteosarcoma patients who were treated between March 2005 and March 2007 in the Pediatrics Department of the Korea Cancer Center Hospital. All patients received neoadjuvant chemotherapy comprising high-dose methotrexate, cisplatin, and adriamycin (doxorubicin) (MMCA). After wide excision, good responders (showing $>90 \%$ necrosis) received the same MMCA adjuvant chemotherapy, whereas poor responders $(n=3)$ received chemotherapy including bleomycin and ifosfamide ${ }^{11)}$. MMCA is neoadjuvant chemotherapy composed of high-dose methotrexate, cisplatin, and doxorubicin. Control group were selected from children and adolescents who participated in 'bone mineral density according to age, bone age, and pubertal stages in Korean children and adolescents' and had 1-year follow-up data of $\mathrm{BMD}^{12)}$.

Age at diagnosis, age at dual-energy $\mathrm{x}$-ray absorptiometry (DXA), sex, tumor location, histologic response to preoperative chemotherapy, chemotherapy regimens, fracture, recurrence, and American Joint Committee on Cancer (AJCC) staging of patients were described. Anthropometric measurements were obtained for each subject before and after chemotherapy. Height was measured without shoes to the nearest $0.1 \mathrm{~cm}$ using a stadiometer (DS-102, Dong Sahn Jenix Co., Seoul, Korea) and weight was measured to the nearest $0.1 \mathrm{~kg}$ on an electronic scale (150A, CAS Co., Seoul, Korea). Bone age and Tanner stage were also assessed in all patients and controls.

DXA was performed for evaluation of BMD before and after chemotherapy. The BMDs of the lumbar spines L1-L4 (BMD $\left.\mathrm{BS}_{\mathrm{S}}\right)$ and unaffected femur neck $\left(\mathrm{BMD}_{\mathrm{FN}}\right)$ were measured serially with a Lunar Prodigy Advance DXA bone densitometer (GE Lunar Corp., Madison, WI, USA) with the software (Ver. En Core 2005 9.15.010; GE Lunar Corp.).

We calculated $z$-scores for the lumbar spines and unaffected femur neck using gender-specific and age-matched Korean pediatric reference data ${ }^{12)} . z$-scores below -2.0 are generally considered 'a low BMD'.

The net BMD or BMD $z$-score change between before and after chemotherapy was assessed using a Wilcoxon signed-rank test. To detect differences between osteosarcoma patients and healthy controls, the ratio of decreased BMD in the lumbar spines and unaffected femur neck during follow-up was assessed using the chi-square test. $P$-values $<0.05$ were considered statistically significant.

Analyses were carried out using SPSS ver. 12.0 (SPSS Inc., Chicago, IL, USA).

\section{Results}

\section{Patients' characteristics}

The clinical characteristics of the patients are summarized in Table 1. There were four males and five females with an average age of $10.5 \pm 3.5$ years (range, $5.5-16.5$ years). Six patients had tumor at the knee joint region (distal femur, 3; proximal tibia, 2; fibular shaft, 1) and three patients had tumor in the upper extremities (proximal humerus, humeral shaft, distal radius). All patients were AJCC stage IIB. Six were good responders and two were poor responders. Patient 9 experienced recurrence. Patient 4 had a femur shaft fracture in affected limb five months after finishing therapy.

\section{Changes in BMD}

The mean interval from the first BMD evaluation to the next BMD evaluation was $7.8 \pm 1.7$ months (range, $6-11$ months). The net changes in $\mathrm{BMD}_{\mathrm{LS}}$ and $\mathrm{BMD}_{\mathrm{FN}}$ are depicted in Fig. 1. Four patients showed decreased $\mathrm{BMD}_{\mathrm{LS}}$ and seven patients showed decreased $\mathrm{BMD}_{\mathrm{FN}}$, while all controls showed increased $\mathrm{BMD}_{\mathrm{LS}}$ and $\mathrm{BMD}_{\mathrm{FN}}(P=0.024$ and $P=0.023)$. Thus, the differences in net $\mathrm{BMD}_{\mathrm{LS}}$ and $\mathrm{BMD}_{\mathrm{FN}}$ of patients from before to after therapy were not significant $(0.033, P=0.097$ and $-0.078, P=0.075)$, while the scores of the control group showed significant increases $(0.036$, $P=0.024$ and $0.055, P=0.023$ ).

In patients, the $\mathrm{BMD}_{\mathrm{LS}} z$-scores changed from $-0.54 \pm 1.43$ to $-0.62 \pm 0.87(-0.082, P=0.769)$ and the $\mathrm{BMD}_{\mathrm{FN}} z$-scores decreased from $-0.49 \pm 1.14$ to $-1.63 \pm 1.50(-1.138, P=0.032)$, while the

Table 1. Characteristics of the patients with osteosarcoma

\begin{tabular}{|c|c|c|c|c|c|c|c|c|c|c|c|c|}
\hline Patient No. & Sex & $\begin{array}{l}\text { Age } \\
(y r)\end{array}$ & $\begin{array}{c}\text { Bone age } \\
(y r)\end{array}$ & $\begin{array}{l}\text { Height } \\
(\mathrm{cm})\end{array}$ & $\begin{array}{l}\text { Weight } \\
(\mathrm{kg})\end{array}$ & $\begin{array}{l}\text { Tanner } \\
\text { stage }\end{array}$ & $\begin{array}{c}\text { AJCC } \\
\text { staging }\end{array}$ & Location & $\begin{array}{c}\text { Chemotherapy } \\
\text { regimen }\end{array}$ & $\begin{array}{c}\text { Response } \\
(\%)\end{array}$ & $\begin{array}{c}\text { BMD }_{L S} \\
\text { z-score }^{a}\end{array}$ & $\begin{array}{c}\text { BMD }_{\mathrm{FN}} \\
\text { z-score }^{\text {a) }}\end{array}$ \\
\hline 1 & $\mathrm{~F}$ & 10.1 & 10 & 130 & 29 & $\|$ & $\| B$ & Femur, distal & MMCA & 100 & -2.93 & -2.09 \\
\hline 2 & M & 7.8 & 6 & 127 & 35 & I & $\| B$ & Fibula, shaft & $\mathrm{MMCA}+\mathrm{CA}$ & NA & 0.82 & -0.04 \\
\hline 3 & M & 16.5 & 18 & 159 & 51 & V & $\| B$ & Femur, distal & MMCA & 100 & -2.42 & -0.46 \\
\hline 4 & M & 12.3 & 14 & 155 & 52 & $\|$ & $\| B$ & Tibia, prox. & MMCA & 95 & 1.09 & -0.65 \\
\hline 5 & $\mathrm{~F}$ & 11.4 & 14 & 149 & 49 & V & $\| B$ & Femur, distal & MMCA & 99 & 0.36 & -0.65 \\
\hline 6 & $\mathrm{~F}$ & 6.6 & 6 & 118 & 21 & I & $\| B$ & Radius, distal & $\mathrm{MMCA}+\mathrm{CAIB}$ & 50 & -0.08 & 1.14 \\
\hline 7 & $\mathrm{~F}$ & 5.5 & 6 & 116 & 22 & । & $\| B$ & Humerus, prox. & $\mathrm{MMCA}+\mathrm{CAIB}$ & 5 & 0.19 & 1.18 \\
\hline 8 & $\mathrm{~F}$ & 10.6 & 11 & 137 & 41 & III & $\| \mathrm{B}$ & Tibia, prox. & MMCA & 95 & -1.58 & -0.97 \\
\hline 9 & M & 13.7 & 17 & 166 & 43 & V & $\| B$ & Humerus, shaft & MMIB & 90 & -0.33 & -1.88 \\
\hline
\end{tabular}


scores of the control group showed no significant changes $(-0.035, P=0.636$ and $0.435, P=0.114)$. After chemotherapy, five patients showed $\mathrm{BMD}_{\mathrm{FN}} Z$-scores below -2.0 , and one patient showed scores between -2 and -1 . Two patients showed $\mathrm{BMD}_{\mathrm{LS}}$ $z$-scores between -2 and -1 .

\section{Characteristics of patients with decreasing $\mathrm{BMD}_{\mathrm{LS}}$}

Among five patients with decreasing $\mathrm{BMD}_{\mathrm{LS}} z$-scores, four underwent additional chemotherapy (such as MMCA+cisplatin, adriamycin, ifosfamide, and bleomycin and high-dose methotrexate, ifosfamide and bleomycin) due to status as a poor responder or tumor recurrence. Three were younger than 8 years.

\section{Discussion}

To our knowledge, the present study is the first to determine the BMD change of lumbar spines and unaffected femur neck in childhood osteosarcoma during treatment including tumor resection and chemotherapy. We found that $77 \%$ of the patients femur neck BMD and 56\% of lumbar spine BMD decreased during treatment. Furthermore, 11\% of the patients had a fracture five months after completing chemotherapy.

Adult cancer patients are well known to be at increased risk of developing osteoporosis as a result of complications from their anticancer therapy ${ }^{13)}$. Bone loss that occurs during cancer therapy is generally more rapid and severe than postmenopausal bone loss in women or normal age-related osteoporosis in men.
Rates of bone loss occurring with cancer therapy can be up to 10 folds higher than normal. Decrease in BMD has also been reported as a consequence of treatments for cancers in children and adolescents ${ }^{6,14-16)}$. Van der Sluis et al. reported that lumbar spine BMD was below -2 standard deviation score (SDS) in $21 \%$ of children with leukemia ${ }^{6}$. Lumbar spine apparent BMD and total body BMD were below -2 SDS in $12 \%$ and $7 \%$, respectively. During chemotherapy, lumbar spine BMD remained below zero and apparent BMD showed no significant changes during the three years of follow-up. Furthermore, the fracture rate increased substantially up to 6 times. Lee et al. ${ }^{16)}$ also reported low BMD in patients during and after chemotherapy for ALL and non-Hodgkin lymphoma, and pamidronate treatment was found to be effective in increasing BMD and alleviating pain in these children. Our study extends the evidence to childhood osteosarcoma, which is the most common malignancy of the extremities in this age group.

In our study, $78 \%$ of the patients' femur neck BMD and $44 \%$ of lumbar spine BMD decreased during treatments. Most children with osteosarcoma had reduced physical activity levels during treatment and frequent immobilization due to surgery and complications related to chemotherapy. Furthermore, decreased outdoor activity levels might induce decreased muscle mass and vitamin $\mathrm{D}$ deficiency as well as decreased $\mathrm{BMD}^{17)}$. We previously reported that those at risk of osteoporosis among longterm survivors of childhood osteosarcoma were those who did not attain puberty, males, and individuals with a low lean mass $^{10)}$. Vitamin D insufficiency is significant as the mineral
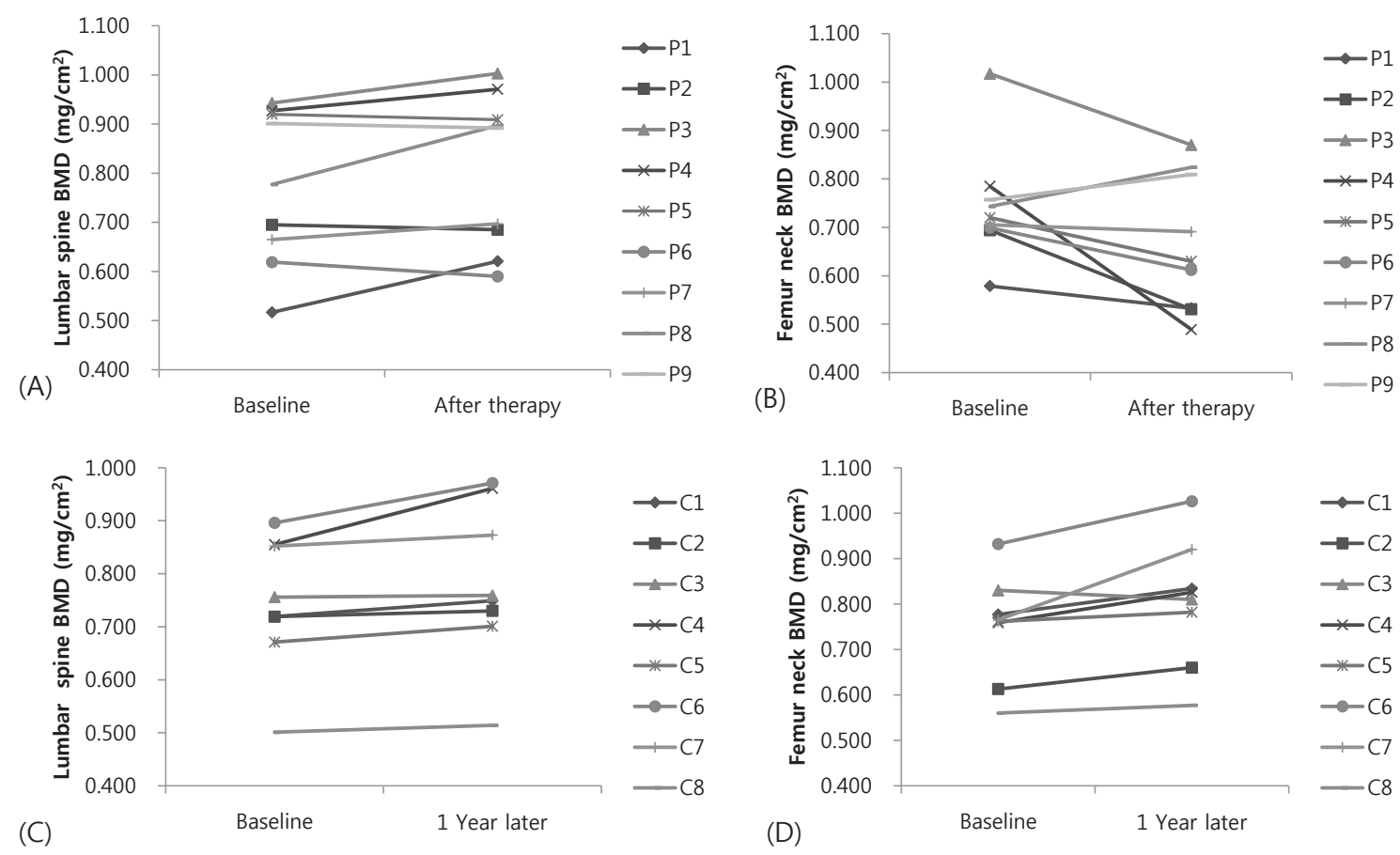

Fig. 1. Comparison of bone mineral density (BMD) changes between osteosarcoma patients and controls. (A) Lumbar spine BMD $\left(\mathrm{mg} / \mathrm{cm}^{2}\right)$ changes of patients. (B) Femur neck BMD changes of patients. (C) Lumbar spine BMD changes of controls. (D) Femur neck BMD changes of controls. Four patients showed decreased lumbar spine BMD and 7 patients showed decreased femur neck BMD, while all controls showed increased BMDs. The interval from first BMD evaluation to next BMD evaluation was 7.8 \pm 1.7 months (vs. $12.0 \pm 0.5$ months in controls). 
is important in calcium absorption, related with parathyroid hormone, and related to BMD acquisition ${ }^{18)}$.

In addition, the four major classes of chemotherapeutic agents with established efficacy in the therapy of osteosarcoma are high-dose methotrexate (MTX), ifosfamide, cisplatin, and doxorubicin. These chemotherapeutic agents are also well known to impair bone mineralization. MTX is effective in eliminating overt pulmonary metastases, improving the opportunity for limb salvage, and healing pathologic fractures in patients with osteosarcoma ${ }^{19)}$. When administered as a sole agent after ablation of the primary tumor, MTX increased survival to $40 \%{ }^{20)}$. In combination with other agents, it increased survival to $65 \%$ to $75 \%{ }^{21,22)}$. However, MTX also suppresses osteoblast activity and stimulates osteoclast recruitment, resulting in decreased bone formation and increased bone resorption $^{23)}$. Higher cumulative doses of MTX have been associated with a greater incidence of osteopenia ${ }^{3)}$. Total doses of more than $4 \mathrm{~g} / \mathrm{m}^{2}$ were associated with a high risk of osteopenia and failure to recover to a normal BMD after completion of therapy ${ }^{9,24)}$. Cyclophosphamide (or ifosfamide) causes hypogonadism, which results in decreased BMD. Estrogens prevent bone resorption and stimulate growth factors necessary for bone growth, and androgens are important in periosteal apposition, which adds strength to the bone $\mathrm{e}^{25)}$. Furthermore, ifosfamide also induces Fanconi syndrome, which can result in hypophosphatemia and, as a consequence, severe metabolic bone disease. Cisplatin induces hypomagnesemia through its renal toxicity, possibly by a direct injury to mechanisms of magnesium reabsorption in the ascending limb of the loop of Henle as well as the distal tubule ${ }^{26)}$. Magnesium deficiency contributes to osteoporosis directly by acting on crystal formation and on bone cells and indirectly by impacting on the secretion and the activity of parathyroid hormone and by promoting low grade inflammation ${ }^{27)}$.

The present study has some limitations. First, selection bias may exist due to the fact that the study was a retrospective chart review of only nine osteosarcoma patients. Second, we could not analyze other factors, such as physical activity and nutrition during therapy, which might decrease BMD.

In conclusion, we found that most childhood osteosarcoma patients showed decreased BMD during treatment including chemotherapy. Therefore, initial evaluation and regular followup of bone health, including BMD measurement, should be performed in all osteosarcoma patients. Furthermore, education regarding preventive measures such as increasing physical activity, sufficient calcium intake, and sunlight exposure should be provided for patients and their parents.

\section{Conflict of interest}

No potential conflict of interest relevant to this article was reported.

\section{References}

1. Cooper C, Westlake S, Harvey N, Javaid K, Dennison E, Hanson M. Review: developmental origins of osteoporotic fracture. Osteoporos Int 2006;17:337-47.

2. Mora S, Gilsanz V. Establishment of peak bone mass. Endocrinol Metab Clin North Am 2003;32:39-63.

3. Pfeilschifter J, Diel IJ. Osteoporosis due to cancer treatment: pathogenesis and management. J Clin Oncol 2000;18:157093.

4. Kang MJ, Lim JS. Bone mineral density deficits in childhood cancer survivors: Pathophysiology, prevalence, screening, and management. Korean J Pediatr 2013;56:60-7.

5. Children's Oncology Group. Long-term follow-up guidelines for survivors of childhood, adolescent, and young adult cancers, ver. 3.0 [Internet]. Philadelphia: Children's Oncology Group; 2012 [cited 2012 Oct 15]. Available from: http://www.survivorshipguidelines.org.

6. van der Sluis IM, van den Heuvel-Eibrink MM, Hahlen K, Krenning EP, de Muinck Keizer-Schrama SM. Altered bone mineral density and body composition, and increased fracture risk in childhood acute lymphoblastic leukemia. J Pediatr 2002;141:204-10.

7. Halton JM, Atkinson SA, Fraher L, Webber C, Gill GJ, Dawson $\mathrm{S}$, et al. Altered mineral metabolism and bone mass in children during treatment for acute lymphoblastic leukemia. J Bone Miner Res 1996;11:1774-83.

8. Luetke A, Meyers PA, Lewis I, Juergens H. Osteosarcoma treatment - where do we stand? A state of the art review. Cancer Treat Rev 2014;40:523-32.

9. Holzer G, Krepler P, Koschat MA, Grampp S, Dominkus M, Kotz R. Bone mineral density in long-term survivors of highly malignant osteosarcoma. J Bone Joint Surg Br 2003;85:231-7.

10. Lim JS, Kim DH, Lee JA, Kim DH, Cho J, Cho WH, et al. Young age at diagnosis, male sex, and decreased lean mass are risk factors of osteoporosis in long-term survivors of osteosarcoma. J Pediatr Hematol Oncol 2013;35:54-60.

11. Lee JA, Kim MS, Kim DH, Lim JS, Park KD, Song WS, et al. Osteosarcoma developed in the period of maximal growth rate have inferior prognosis. J Pediatr Hematol Oncol 2008;30:419-24.

12. Lim JS, Hwang JS, Lee JA, Kim DH, Park KD, Cheon GJ, et al. Bone mineral density according to age, bone age, and pubertal stages in korean children and adolescents. J Clin Densitom 2010;13:68-76.

13. Guise TA. Bone loss and fracture risk associated with cancer therapy. Oncologis. 2006;11:1121-31.

14. van der Sluis IM, van den Heuvel-Eibrink MM. Osteoporosis in children with cancer. Pediatr Blood Cancer 2008;50(2 Suppl):474-8.

15. Athanassiadou F, Tragiannidis A, Rousso I, Katsos G, Sidi V, Koliouskas D, et al. Evaluation of bone metabolism in children with acute lymphoblastic leukemia after induction chemotherapy treatment. Pediatr Hematol Oncol 
2005;22:285-9.

16. Lee JM, Kim JE, Bae SH, Hah JO. Efficacy of pamidronate in children with low bone mineral density during and after chemotherapy for acute lymphoblastic leukemia and nonHodgkin lymphoma. Blood Res 2013;48:99-106.

17. Wasilewski-Masker K, Kaste SC, Hudson MM, Esiashvili $\mathrm{N}$, Mattano LA, Meacham LR. Bone mineral density deficits in survivors of childhood cancer: long-term followup guidelines and review of the literature. Pediatrics 2008;121:e705-13.

18. Joo NS, Dawson-Hughes B, Kim YS, Oh K, Yeum KJ. Impact of calcium and vitamin $\mathrm{D}$ insufficiencies on serum parathyroid hormone and bone mineral density: analysis of the fourth and fifth Korea National Health and Nutrition Examination Survey (KNHANES IV-3, 2009 and KNHANES V-1, 2010). J Bone Miner Res 2013;28:764-70.

19. Jaffe N, Link MP, Cohen D, Traggis D, Frei E 3rd, Watts H, et al. High-dose methotrexate in osteogenic sarcoma. Natl Cancer Inst Monogr 1981;(56):201-6.

20. Goorin AM, Delorey M, Gelber RD, Perez-Atayde A, Gebhardt M, Andersen JW, et al. The Dana Farber Cancer Institute/The children's hospital adjuvant chemotherapy trials for osteosarcoma: three sequential studies. Cancer Treat Symp 1985;3:155-9.

21. Meyers PA, Gorlick R, Heller G, Casper E, Lane J, Huvos $\mathrm{AG}$, et al. Intensification of preoperative chemotherapy for osteogenic sarcoma: results of the Memorial SloanKettering (T12) protocol. J Clin Oncol 1998;16:2452-8.

22. Kim MS, Cho WH, Song WS, Lee SY, Jeon DG. Time dependency of prognostic factors in patients with stage II osteosarcomas. Clin Orthop Relat Res 2007;463:157-65.

23. May KP, West SG, McDermott MT, Huffer WE. The effect of low-dose methotrexate on bone metabolism and histomorphometry in rats. Arthritis Rheum 1994;37:201-6.

24. Mandel K, Atkinson S, Barr RD, Pencharz P. Skeletal morbidity in childhood acute lymphoblastic leukemia. J Clin Oncol 2004;22:1215-21.

25. Syed F, Khosla S. Mechanisms of sex steroid effects on bone. Biochem Biophys Res Commun 2005;328:688-96.

26. Lajer H, Daugaard G. Cisplatin and hypomagnesemia. Cancer Treat Rev 1999;25:47-58.

27. Castiglioni S, Cazzaniga A, Albisetti W, Maier JA. Magnesium and osteoporosis: current state of knowledge and future research directions. Nutrients 2013;5:3022-33. 